\title{
ABSOLUTE CONFIGURATION OF 18-ACETOXY-CIS-CLERODA-3,13E-DIEN-15-OIC ACID
}

\author{
IVÁN BRITO ${ }^{*}$, JORGE BÓRQUEZ ${ }^{1}$, DIEGO ROBLEDO', MARIO J. SIMIRGIOTIS ${ }^{2}$ AND \\ ALEJANDRO CÁRDENAS
}

\author{
${ }^{1}$ Departamento de Química, Facultad de Ciencias Básicas, Universidad de Antofagasta, Casilla 170, Antofagasta, 1240000, Chile. \\ ${ }^{2}$ Instituto de Farmacia, Facultad de Ciencias, Universidad Austral de Chile, Casilla 567, Valdivia 5090000, Chile. \\ ${ }^{3}$ Departamento de Física, Facultad de Ciencias Básicas, Universidad de Antofagasta, Casilla 170, Antofagasta, 1240000, Chile.
}

\begin{abstract}
In this paper we report the absolute configuration which has been determined from the refinement of the Flack parameter, $\mathrm{x}=0.05(5)$, which indicate that the correct configuration had been assigned against $1353(99 \%) \mathrm{CuK} \alpha$ Bijvoet pairs. On this basis the absolute configuration was assigned as $\mathrm{C} 5 R$, $\mathrm{C} 8 S$, $\mathrm{C} 9 R$ and $\mathrm{C} 10 S$. The structure of 18-acetoxy-cis-cleroda-3,13E-dien-15-oic acid consists of a clerodane skeleton and the corresponding methyl groups are $\alpha$-oriented (C8, C9) while $\mathrm{C} 5$ is $\beta$-oriented. The acidic lateral chain is $\beta$-oriented and the double bond between $\mathrm{C} 13$ and $\mathrm{C} 14$ has $\mathrm{E}$ isomeric. The ciclohexene, cyclohexane rings are cis fused, and in an sofa and chair conformation respectively. In the crystal the molecules are linked by one intermolecular $\mathrm{O}-\mathrm{H} \ldots \mathrm{O}$ hydrogen bond forming 1D-dimensional chain with distance donor-acceptor of $2.060(6) \AA$ with graph-set notation $C_{1}^{1}(15)$.
\end{abstract}

\section{INTRODUCTION}

Following our program to isolate interesting metabolites from the Atacama Desert Flora, Northern Chile ${ }^{10,12-17}$. Now we are dedicated to the study of Haplopappus rigidus Phil., one of the species known in Chile by the popular name "baylahuen", is an endemic plant found at a height of over $3000 \mathrm{~m}$ in the Andes mountains and used as medicinal by the local population and Aymara aboriginals since precolombian times ${ }^{1}$. All the related Chilean Haplopappus "baylahuen" species produce a resinous exudate with interesting biologically active compounds including, several clerodane and labdane diterpenoids and flavonoids with biological significance ${ }^{2}$. Indeed, the Mapuche medicinal plants Haplopappus multifolius, H. taeda, H. baylahuen and remyanus showed the presence of flavonoids and labdane terpenoids with known antioxidant, choleretic, anti-inflammatory and cholagogue properties ${ }^{3,4,5}$. In the Aymara region, the infusion of $H$. rigidus has been used to cure or prevent liver diseases, gastro-intestinal disorders, cough and has also been employed as a sexual stimulant attributed to the presence of diterpenoids and flavonoids ${ }^{1,6,7}$. Moreover, from the resinous exudate of $H$. incinatus the antibacterial potent clerodane diterpenoid: 18-acetoxy-cis-cleroda-3-en-15-oic acid was isolated ${ }^{2,8}$, while from the aerial parts of $H$. rigidus Phil, the related main clerodane rigidusol (13-hydroxy-18-acetoxy-cis-cleroda-3,14-diene) exhibited moderate cytotoxic activity against human breast adenocarcinoma cell line MCF- $7^{9}$. In this work we report the absolute configuration of the rigidusol derivative 18-acetoxy-ciscleroda-3,13E-dien-15-oic acid by X-ray diffraction methods, which is consistent with the previously reported for this compound ${ }^{2,8}$ (Figure 1).

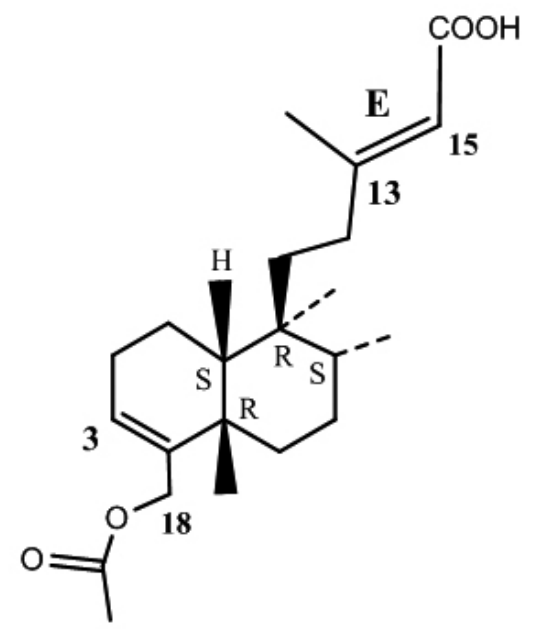

Figure 1. Absolute configuration of 18-acetoxy-cis-cleroda-3,13E-dien15-oic acid.

\section{EXPERIMENTAL}

The title compound $\mathrm{C}_{22} \mathrm{H}_{34} \mathrm{O}_{4}$, is a clerodane diterpenoid firstly isolated from aerial parts of Croton chilensis (Muell. Arg) and identified as 18-acetoxycis-cleroda-3,13E-dien-15-oic acid by spectral data and relative configuration by X-ray diffraction methods ${ }^{10}$. The later compound was also isolated and reported from Haplopappus deserticola ${ }^{11}$. Following our program to isolate interesting metabolites from the Atacama Desert Flora, Northern Chile ${ }^{12-18}$, dried aerial parts of Haplopappus rigidus (1050 g) collected in april 2015 in "El Tatio", Andean mountain range of the of Atacama Desert, II Region, Northern Chile, were defatted with hexane (3 liters, 3 times in the dark, 24 hours each time) and $58.88 \mathrm{~g}$ were obtained after evaporation of a ethyl acetate solution. A portion of the extract $(30.30 \mathrm{~g})$ was filtered and submitted to a medium pressure column chromatography system composed of an $2.5 \mathrm{~cm} x$ $48 \mathrm{~cm}$ medium pressure column (Aceglass inc, Vineland, NY, USA) packed with silicagel (Kieselgel $60 \mathrm{H}$, Merck, Darmstadt, Germany) using an isocratic solvent system of n-hexane-ethyl acetate $(9.5: 0.5 \mathrm{v}: \mathrm{v})$ pumped with a medium pressure pump (FMI lab pump, Syosset, NY, USA) with a flow rate of 10 mL-minute. The collected fractions (226) were combined according to TLC analysis (Kieselgel F254 plates, developed with Hexane: EtOAc 7:3 v/v and spots visualized by spraying with vanillin: sulfuric acid $2 \%$ in ethanol and heating). From fractions 24-37, the known compound: 13-hydroxy-18acetoxy-cis-cleroda-3,14-diene ${ }^{9}(2.42 \mathrm{~g})$ was isolated and from fractions 94 135 the known compound 1 (18-acetoxy-cis-cleroda-3,13E-dien-15-oic acid, $1.53 \mathrm{~g}$ ) was isolated previously from the botanic specie Croton chilensis ${ }^{10}$

Recrystallization from ethyl acetate/n-hexane a room temperature yielded pure white crystals of the last compound, suitable for X-ray diffraction analysis.

The relative stereochemistry of the title compound was assigned by spectroscopic data and by chemical transformations ${ }^{8}$. In this paper we report the absolute configuration of the title compound which has been determined from the refinement of the Flack parameter ${ }^{19}, \mathrm{x}=0.0(5)$, which indicate that the correct configuration had been assigned against 1353 (99\%) $\mathrm{CuK} \alpha$ Bijvoet pairs. On this basis the absolute configuration was assigned as $\mathrm{C} 5 R, \mathrm{C} 8 \mathrm{~S}, \mathrm{C} 9 R$ and $\mathrm{C} 10 \mathrm{~S}$.

White crystals, m.p. $100-102{ }^{\circ} \mathrm{C}$. The molecular weight was determined by Q-orbitrap HESI-MS/MS with a mass spectrometer (Q-exactive Focus, Bremen, Germany) [M-H] : 361.23825 calcd. for $\mathrm{C}_{22} \mathrm{H}_{33} \mathrm{O}_{4}: 361.23843$ (Figure 2). ${ }^{1} \mathrm{H}$ NMR (Bruker Avance $\left.300 \mathrm{MHz}, \mathrm{CDCl}_{3}\right) \stackrel{22}{\delta} \mathrm{ppm}: 5.70(2 \mathrm{H}, \mathrm{s}$, H-3/H-14), 4.59 (2H, s, H-18), 2.19 (3H, s, Me-16), 2.16 (2H, m, H-2), 2.07 $\left(3 \mathrm{H}, \mathrm{s}, \mathrm{COCH}_{3}\right), 2.03(1 \mathrm{H}, \mathrm{m}, \mathrm{H}-1), 2.01(2 \mathrm{H}, \mathrm{m}, \mathrm{H}-12), 1.95(1 \mathrm{H}, \mathrm{m}, \mathrm{H}-6)$ $1.81\left(1 \mathrm{H}, \mathrm{m}, \mathrm{H}-1^{\prime}\right), 1.62(1 \mathrm{H}, \mathrm{m}, \mathrm{H}-11), 1.42\left(2 \mathrm{H}, \mathrm{m}, \mathrm{H}-8 / \mathrm{H}-11^{\prime}\right), 1.36(2 \mathrm{H}, \mathrm{m}$, H-7/H-10), 1.29 (2H, m, H-6/H-7'), 1.19 (3H, s, Me-19), 0.79 (3H, s, Me-20), $0.77(3 \mathrm{H}, \mathrm{s}, \mathrm{Me}-17) .{ }^{13} \mathrm{C}$ NMR $\left({ }^{13} \mathrm{C}\right.$ NMR Bruker Avance $\left.75 \mathrm{MHz}, \mathrm{DMSO}-\mathrm{d6}\right)$ $\delta$ ppm: 17.2 (C-1), 23.9 (C-2), 129.2 (C-3), 138.2 (C-4), 40.20 (C-5), 37.1 (C-6), 28.7 (C-7), 37.5 (C-8), 36.3 (C-9), 45.1 (C-10), 36.1 (C-11), 34.7 (C12), 164.6 (C-13), 114.8 (C-14), 170.9 (C-15), 19.5 (C-16), 15.9 (C-17), 66.6 (C-18), 34.6 (19), 17.2 (20), 171.0 (21), 21.2 (C-22). These data, together with ESI-MS/MS and correlations observed in the HSQC and HMBC spectra, are consistent with the structure of 18-acetoxy-cis-cleroda-3,13E-dien-15-oic acid 
(Figures 1 and 3) confirmed by comparison of spectroscopic data with those reported in the literature for this structure ${ }^{8-11}$.

Data collection, structural determination and refinement was performed with a Bruker AXS D8-Venture, Triumph- $\mu \mathrm{I}-\mathrm{Cu}$ with graphite-monochromated $\mathrm{CuK} \alpha$ radiation $(1.54178 \AA)$. The structure was solved by direct method, and was refined against $\mathrm{F}^{2}$ by full-matrix least-squares methods using SHELXL ${ }^{20}$. All of the non-hydrogen atoms were refined anisotropically. The hydrogen atoms was located from a difference Fourier map and allowed to ride on their parent $\mathrm{C}$ and $\mathrm{O}$ atoms, with isotropic displacement parameters related to the refined values of the corresponding parent atoms. The final Fourier maps, the electron-density residuals were not significant. Crystallographic data, details of data collection and structure refinement parameters for the title compound is summarized in Table 1. Program used to solve structure: SHELXS-201320, program used to refine structure: SHELXL-2013 ${ }^{20}$, molecular graphics ${ }^{21}$.

\section{RESULTS AND DISCUSSION}

The X-ray crystal-structure determination of the title compound was undertaken in order to establish its absolute configuration. The structure of 18-acetoxy-cis-cleroda-3,13E-dien-15-oic acid consists of a clerodane skeleton and the corresponding methyl groups are $\alpha$-oriented $(\mathrm{C} 8, \mathrm{C} 9)$ while C5 is $\beta$-oriented. The acidic lateral chain is $\beta$-oriented and the double bond between $\mathrm{C} 13$ and $\mathrm{C} 14$ has a $\mathrm{E}$ isomeric configuration.

The Cremer and Pople parameters ${ }^{22}$ for the ciclohexene and ciclohexane rings are:

$\mathrm{Q}_{\mathrm{T}}=0.455(10) \AA, \theta=134.4(13)^{\circ}, \varphi=115.2(17)^{\circ}$ and $\mathrm{Q}_{\mathrm{T}}=0.560(9) \AA, \theta=$ $12.7(9)^{\circ}, \varphi=179.4(4)^{\circ}$ so the onformation is sofa and chair respectively. The ciclohexene, ciclohexane rings are cis fused. In the crystal the molecules are linked by one intermolecular $\mathrm{O}-\mathrm{H} \cdots \mathrm{O}$ hydrogen bond forming $1 \mathrm{D}$-dimensional chain with graph-set notation $(15)^{23}\left(\mathrm{O} 2-\mathrm{H} 2 \cdots \mathrm{O}^{\mathrm{i}}{ }^{149^{\circ}}\right.$; O2 $\cdots \mathrm{O}^{\mathrm{i}} 2.797(9)$ $\AA ; \mathrm{H} 2 \cdots \mathrm{O} 4^{\mathrm{i}} 2.06 \AA$ (symmetry code (i) $\mathrm{x},-1+\mathrm{y}, 1+\mathrm{z}$ ), (Figure 4). The absolute configuration of the title compound which has been determined from the refinement of the Flack parameter ${ }^{19}, \mathrm{x}=0.0(5)$, which indicate that the correct configuration had been assigned against 1353 (99\%) CuK $\alpha$ Bijvoet pairs. On this basis the absolute configuration was assigned as $\mathrm{C} 5 R, \mathrm{C} 8 S, \mathrm{C} 9 \mathrm{R}$ and $\mathrm{C} 10 \mathrm{~S}$. All distances and angles are normal.

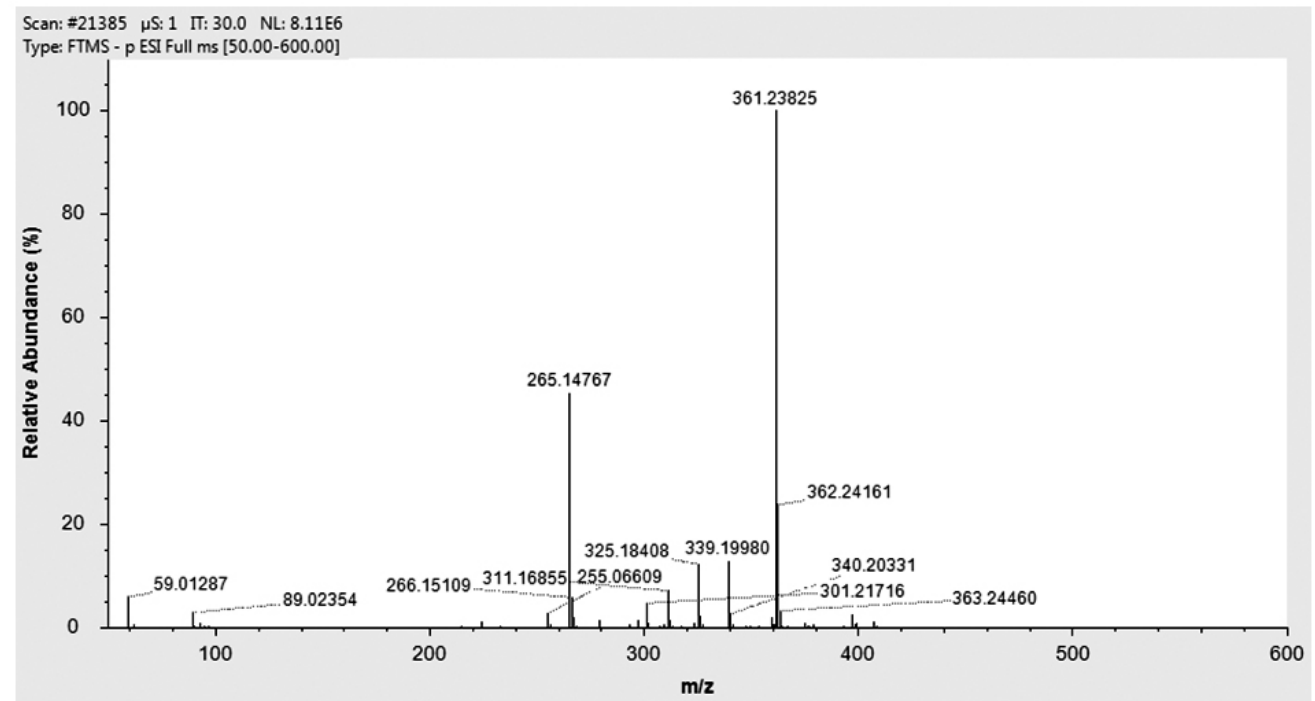

Figure 2. Full Q-Orbitrap HESI (-) spectra of compound 18-acetoxy-cis-cleroda-3,13E-dien-15-oic acid.

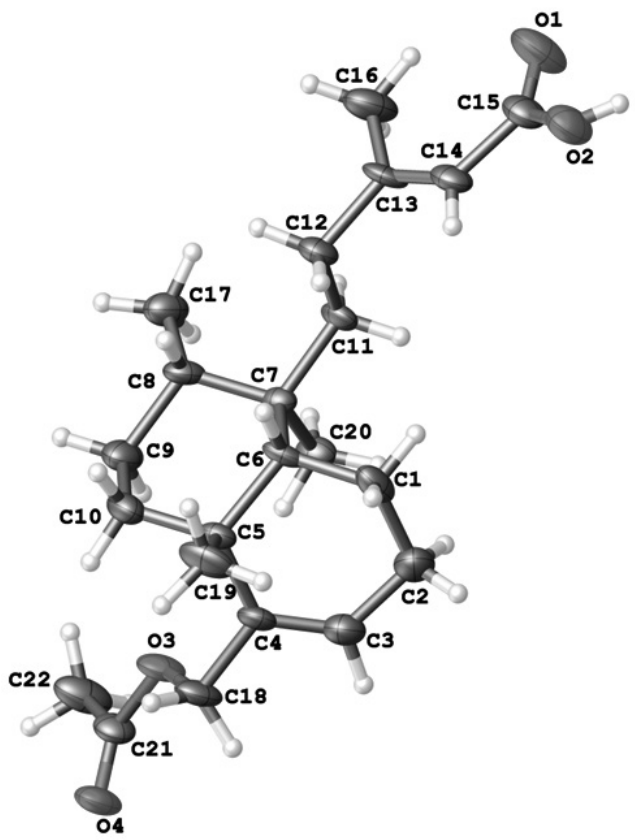

Figure 3. ORTEP Diagram of 18-acetoxy-cis-cleroda-3,13E-dien-15-oic acid. The ellipsoids are shown at the $30 \%$ probability level. 


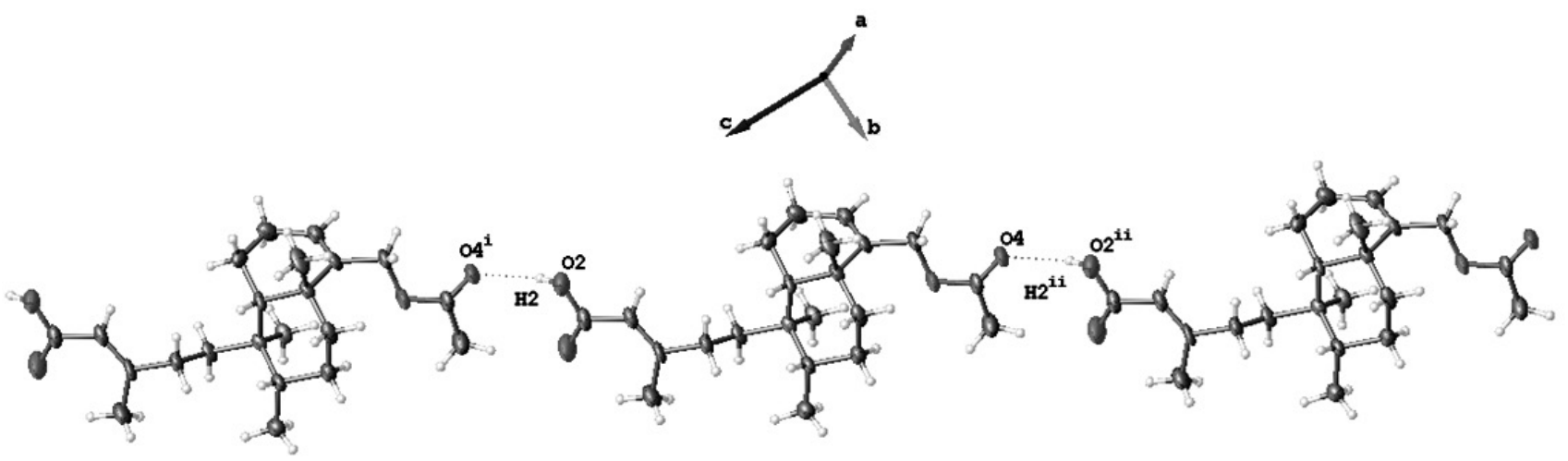

Figure 4. A view of the one-dimensional supramolecular aggregate, showing the formation of chain with set-graph motif $(15)^{23}$. [Symmetry codes: (i) $\mathrm{x},-1+\mathrm{y}, 1+\mathrm{z}$; (ii) $\mathrm{x}, 1+\mathrm{y},-1+\mathrm{z}$ ].

Table 1. Crystallographic data, details of data collection and structure refinement parameters for the title compound.

\section{Crystal data}

$$
\begin{array}{ll}
\mathrm{C}_{22} \mathrm{H}_{34} \mathrm{O}_{4} & \\
\mathrm{Mr}=362.49 & \\
\text { Monoclinic, } \mathrm{P} 21 & \\
\mathrm{a}=10.0779(11) \AA & \alpha=90^{\circ} \\
\mathrm{b}=8.0098(9) \AA & \beta=109.788(7)^{\circ} \\
\mathrm{c}=13.6747(13) \AA & \gamma=90^{\circ}
\end{array}
$$

Density (calculated) $/ \mathrm{Mg} / \mathrm{m}^{3} \quad 1.159$

$$
\begin{aligned}
& \mathrm{V}=1038.7(2) \AA^{3} \\
& \mathrm{Z}=2 \\
& \mathrm{CuK} \alpha(\lambda=1.54178 \AA) \\
& \mu=0.62 \mathrm{~mm}^{-1} \\
& \mathrm{~T}=296(2) \mathrm{K}
\end{aligned}
$$

Colourless, Block, $0.180 \times 0.170 \times 0.09 \mathrm{~mm}$

$\mathrm{F}(000)=396$

\section{Data Collection}

Diffractometer Bruker AXS D8-Venture, Triumph-I $\mu-\mathrm{Cu}$

1485 reflections with $\mathrm{I}>2 \sigma(\mathrm{I})$

15972 measured reflections

2972 independentreflections

$2 \theta$ range for data collection

6.870 to $118.01^{\circ}$

Index ranges

$$
-11 \leq \mathrm{h} \leq 11,-8 \leq \mathrm{k} \leq 8,-15 \leq 1 \leq 15
$$

\section{Refinement}

$$
\begin{aligned}
& \mathrm{R}\left[\mathrm{F}^{2}>2 \sigma\left(\mathrm{F}^{2}\right)\right]=0.069 \\
& \mathrm{wR}\left[\mathrm{F}^{2}\right]=0.183 \\
& \Delta \rho_{\max }=0.22 \mathrm{e} \cdot \AA^{-3} \\
& \Delta \rho_{\min }=-0.20 \mathrm{e} \cdot \AA^{-3}
\end{aligned}
$$

\author{
241 parameters \\ Flack parameter ${ }^{19} 0.0(5)$ \\ Number Bijvoet pairs: $1353(99 \%)$ \\ $\mathrm{S}=0.94$
}

\section{CONCLUSIONS}

In the title compound the molecular structure and its relative configuration were established by spectroscopic and crystallographic methods twenty three year ago $^{10}$, but not of the absolute configuration, due to the experiment condition used (Mo, radiation). In order to establish its absolute configuration, a single-crystal X-ray diffraction analysis of was undertaken, using $\mathrm{Cu}$ radiation. The X-ray molecular model of the title compound ( Figure 3), confirmed all the above deductions on its structure and established the absolute configuration as $\mathrm{C} 5 R, \mathrm{C} 8 \mathrm{~S}, \mathrm{C} 9 \mathrm{R}$ and $\mathrm{C} 10 \mathrm{~S}$.
Supplementary material

CCDC-1812263 contains the supplementary crystallographic data for this paper. These data can be obtained free of charge from the Cambridge Crystallographic Data Centre via www.ccdc.cam.as.uk/data_request/cif.

\section{ACKNOWLEDGEMENTS}

IB acknowledgment Fondequip Program (Grant EQM130021) for the funding to purchase Single Crystal X- ray Diffractometer. JB \& MS thanks FONDECYT (Chile) (Grant 1180059) and Fondequip (EQM140002) for financial support. 


\section{REFERENCES}

1. M. Montes, T. Wilkomirsky. Medicina Tradicional Chilena, Universidad de Concepción, Concepción, p. 193, (1985)

2. A. Urzua, R. Torres, M. Muñoz, Y.Palacios.Journal of Ethnopharmacology, 45, 71, (1995)

3. H.Vogel, M. González, F. Faini, I. Razmilic, J. Rodriguez, J.S. Martin and F. Urbina Journal of Ethnopharmacology 97, 97-100, (2005)

4. F. Faini, R. Torres, J.M. Rodilla, C. Labbe,C. Delporte and F. Jaña. J. Braz. Chem. Soc. 22, 2344, (2011)

5. G. Schmeda-Hirschmann, C. Quispe and B. González. Molecules. 20, 913, (2015)

6. G.E. Wickens. Vegetation and ethnobotany of the Atacama Desert and adjacent Andes northern Chile. Opera Bot., 121, 291, (1993)

7. N. Monterrey. Hierbas Medicinales Andinas $2^{\text {a }}$ Región. Ministerio de Educación, Antofagasta, p. 35, (1996)

8. A. Urzua, F. Jara, E. Tojo, M. Wilkens, L. Mendoza, M.M. Rezende. Journal of Ethnopharmacology 297, 103, (2006)

9. G. Morales, P. Sierra, L.A. Loyola, J. Bórquez. Phytochemistry. 55, 863, (2000).

10. J. Bórquez, A. Mancilla, S. Pedreros, L.A. Loyola, G. Morales, O. Wittke, I. Brito. Bol. Soc. Chil. Quím., 40, 157, (1995)

11. E. Tojo, M.E. Rial, A. Urzua, L. Mendoza. Phytochemistry, 52, 1531, (1999)
12. J. Bórquez, A. Ardiles, L.A. Loyola, L.M. Peña-Rodriguez, G.M. MolinaSalinas, J. Vallejos, G. Isidro, I.G. Collado, M.J. Simirgiotis. Molecules, 19, 3898, (2014)

13. J. Bórquez, C. Echiburú-Chau, P. Winterhalter, J. Vallejos, G. Jerz, M.J. Simirgiotis.. Journal of Science of Food and Agriculture, 96, 2832, (2016)

14. J. Borquez, E.J. Kennelly and M.J. Simirgiotis. Food Research International 52, 288, (2013)

15. I. Brito, J. Borquez, M. Simirgiotis, A. Cardenas and M. Lopez-Rodriguez. Acta Crystallographica Section E-Structure Reports Online. E68, 032. (2012).

16. I. Brito, J. Bórquez, M.J. Simirgiotis, M. Neves-Vieira, G. Jerz, P Winterhalter, M. Bolte, A. Cárdenas. Zeitschrift für KristallographieNew Crystal Structures, 229, 399, (2014)

17. I. Brito, M.J. Simirgiotis, R. Muñoz, J. Benites, L. Pasten, J. Bórquez, A Cárdenas. Zeitschrift für Kristallographie-New Crystal Structures, 232, 13, (2017) Simirgiotis. Saudi Pharmaceutical Journal 25, 1032, (2017)

19. H.D. Flack. Acta Cryst. A39, 876, (1983)

20. G. M. Sheldrick, Acta Cryst. 112, A64, (2008)

21. O.V. Dolomanov, L.J. Bourhis, R.J. Gildea, J.A.K. Howard, H. Puschmann, J. Appl. Cryst., 42, 339, (2009)

22. D.Cremer, J.A. Pople. J.Am.Chem.Soc. 97, 1354, (1975)

23. J. Bernstein, R.E. Davis, L. Shimoni, N.-L. Chang. Angew. Chem. Int. Ed. Engl. 34, 1555, (1995) 